\title{
Turning Food Waste into Value-Added Resources: Current Status and Regulatory Promotion in Taiwan
}

\author{
Wen-Tien Tsai \\ Graduate Institute of Bioresources, National Pingtung University of Science and Technology, Pingtung 912, \\ Taiwan; wttsai@mail.npust.edu.tw; Tel.: +886-8-7703202
}

Received: 25 February 2020; Accepted: 28 April 2020; Published: 30 April 2020

\begin{abstract}
Food waste is daily generated in significant amounts around the world, implying the depletion of natural resources and the emergence of environmental pollution issues if discarded without valorization or utilization. In this regard, food waste management poses an important challenge in the circular society. Based on the official statistics and the national laws and regulations database in Taiwan, this study analyzed the on-line reporting amounts of collected food waste since it has been officially designated as one of the mandatory recyclable wastes. Furthermore, the regulatory measures for promoting food waste utilization in Taiwan were addressed to valorize it for the production of value-added resources and also prevent the spread of African swine flu. It showed that the collected amounts of food waste from residential and commercial sectors in Taiwan significantly increased from about 168,600 metric tons in 2003 to the maximal amount (i.e., 834,500 metric tons) in 2012, reflecting the regulatory promulgation and promotional measures. Based on the joint efforts by the central governing authorities (including the Environmental Protection Administration, the Council of Agriculture, and the Ministry of Economic Affairs), this study also examined the regulatory promotions for utilizing food waste as an available resource for the production of value-added resources (i.e., organic fertilizer, pig feed, and bioenergy). Through the central governing authority, local governments, and private recyclers, about 2000 metric tons of food waste in Taiwan was recycled every day, which can not only mitigate the pressure on waste incineration and disposal systems, but also conform to the trends of environmental sustainability and circular bioeconomy. Therefore, the Taiwan government is currently supporting the establishment of anaerobic digestion and aerobic composting plants for turning food waste into organic fertilizers and biogas-to-electricity because they have been evaluated as the best options of food waste valorization.
\end{abstract}

Keywords: food waste; valorization; composting; pig feed; bioenergy; regulatory promotion

\section{Introduction}

The increase in living levels and changes in eating habits have led to plenty of food waste generated from residences and commercial service establishments, such as restaurants, institutional cafeterias, and hotels, as well as from industrial sources like employee lunchrooms. The discarded waste often contained leftover meals and grains, vegetable leaves, fruit peelings, dairy, and scraped food. Due to its biological constituents and water involved, the food waste was associated with public health problems if it is illegally disposed off in dumping sites [1], such as malodor, water pollution, greenhouse gas emissions, and infectious disease caused by breeding flies and mosquitoes. Therefore, food waste was traditionally treated by sanitary landfilling, incineration, composting, and animal feeds (or feed ingredients) [2,3]. However, these options could cause secondary pollution and additional energy consumption. In recent years, the circular bioeconomy of food waste has been addressed to transform its linear economy into a sustainable biorefinery [4,5]. Therefore, the recycling of food waste as a valuable resource for the production of chemicals, materials, and fuels has been highlighted 
in most countries [6-12]. As compared to other Asian developing countries (e.g., Thailand and Malaysia), and based on the utilization rates $[3,13,14]$, the food waste valorization in developed countries (e.g., Taiwan, South Korea, Australia, and Sweden) is a learnable model because these countries had higher rates by adapting a "zero waste and resource recycling" policy.

In Taiwan, about $20 \mathrm{wt} \%$ of the municipal solid waste (MSD) is food waste. The kitchen waste is derived from leftover meals, vegetables, and fruits, which mainly included moisture, carbohydrates, proteins, and oils [1]. Traditionally, most food waste in the residential sector was locally collected by private recyclers to reuse it as a pig feed to cut the costs given the carbohydrate/protein-based feeds that need to be purchased. In addition, some pig farmers preferred to use swill because its high fat content contributed to black Iberian pigs producing flavorful pork. The remaining food waste was mostly sent to private composting systems and public incineration/landfill systems. Therefore, starting from 2001, the central governing agency (i.e., the Environmental Protection Administration, also known as the EPA) promulgated the regulation governing the valorization of food waste from general waste and industrial waste by designating it as a mandatory recyclable waste $[15,16]$. Meanwhile, the EPA also provided the subsidies for the local governments to establish their food waste collection and valorization programs. According to the official statistics [17], the collected amounts of food waste indicated an increasing trend from 168,600 metric tons in 2003 to 834,500 metric tons in 2012, but subsequent inclination was observed mainly due to the reduction in the composting treatment capacity and the pig feed (stricter environmental standards in the livestock industry, described in Section 3.2) [18]. Meanwhile, the EPA began focusing on the valorization of food waste by upgrading the composting processes in the existing private compost treatment facilities via subsidiary supports. These private composting companies, contracted with the EPA, recycled the food waste collected from local governments. This public-private partnership model thus encouraged the private sector to invest more technological and marketing resources for turning food waste into valuable resources like organic fertilizer and biogas energy. More importantly, these composting facilities not only meet the environmental regulations, but their composts can conform to the official specifications for organic fertilizers. On the other hand, the issues of food waste valorization for the production of biogas-to-power (bioenergy) and the prevention of African swine fever (ASF) spread have been highlighted in recent years [19-21].

Regarding the regulatory and promotional measures for mandatory valorization of food waste from the residential and commercial sectors, there are fewer cases currently available in the literature. From the viewpoints of both environmental sustainability and the circular bioeconomy, an evaluation of the information about the strategies and practices of food waste valorization in Taiwan would be valuable. This paper reports on a study of food waste valorization in Taiwan, which was structured by two key issues. First, the collection system, on-line reporting amount, and valorization status of food waste since 2003 will be addressed in Section 3.1 to analyze the trends. The regulatory promotions for turning food waste into value-added resources were then studied in Section 3.2, based on the joint-efforts by the central governing authorities.

\section{Methodology}

In order to describe the methodology, Figure 1 shows a simple flowchart of the sequence of steps in this work. As mentioned above, the main purposes of this study were to analyze the status of food waste management (collection and reuse), and further address its regulatory measures in Taiwan. The statistical data, valorization methods, and regulatory measures were briefly summarized below. 


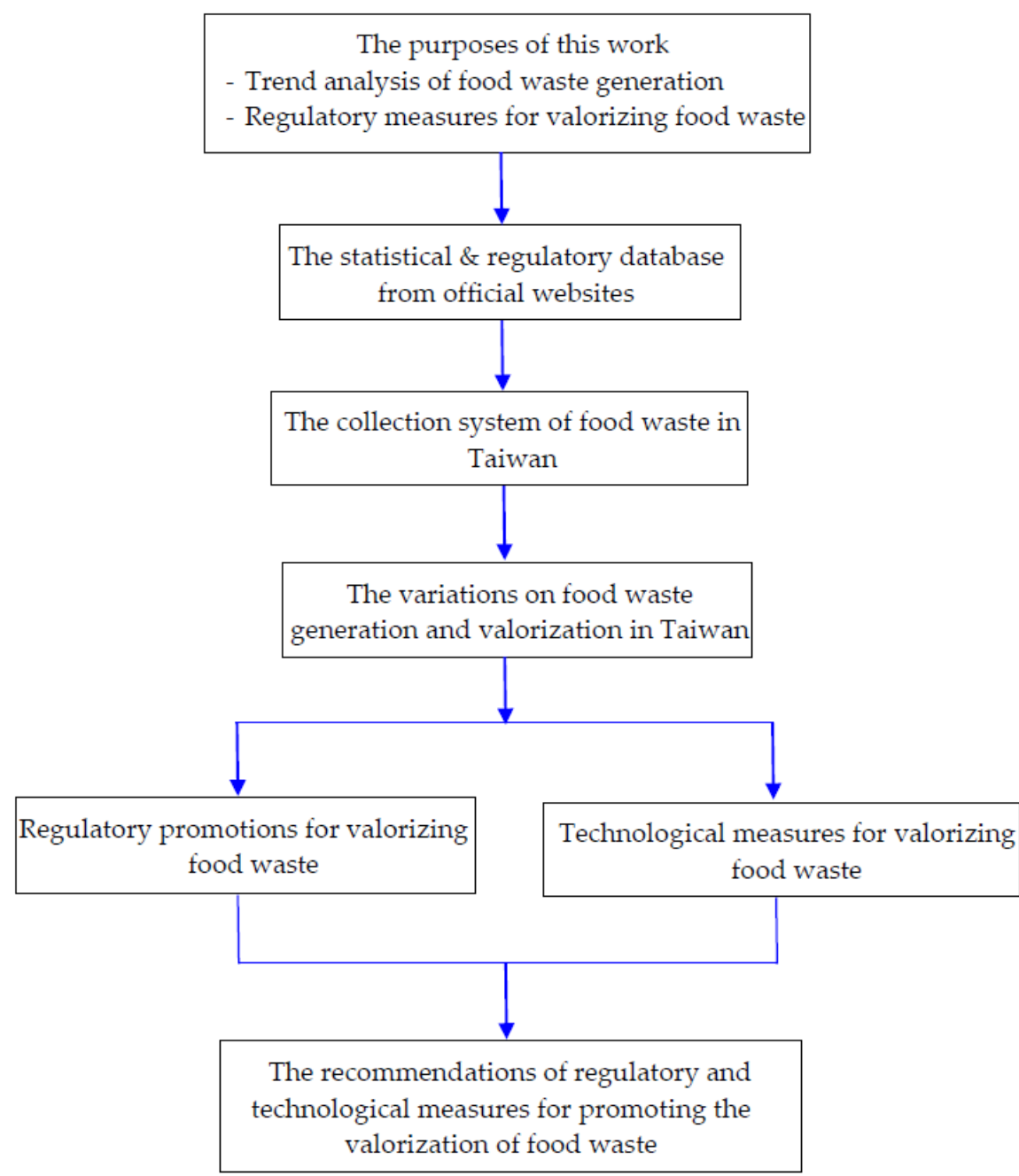

Figure 1. A flowchart of the major steps of the proposed methodology in this work.

- Activity (statistics and status) of food waste management: The updated data on the statistics and status of food waste management in Taiwan were obtained from the official yearbook [17], which was compiled by the EPA.

- Technological valorization methods: In order to highlight current valorization methods in Taiwan, food waste valorization options, including composting, pig feed, and others, were extracted from the academic database like Web of Science and Google Scholar.

- Regulatory measures for turning food waste into valuable resources: The information about the regulatory measures for turning food waste into valuable resources was accessed on the official website [22], including the EPA, the Council of Agriculture (COA), and the Ministry of Economic Affairs (MOEA).

\section{Results and Discussion}

In line with the new trends of sustainable resources and zero waste, the Taiwan EPA promoted the "Resource Recycling Four-in-One Program" ("4-in-1") in 1997 [15], which integrated residents, private recyclers, local governments, and non-profit recycling funds to carry out resource recycling and waste minimization. Furthermore, the EPA began to implement waste minimization at the source, compulsory household garbage sorting, and expanded the scope of waste recycling since 2002. Since then, the program has largely increased the recycling rate of mandatory recyclable wastes. The EPA further promoted the recycling of food waste from 2003. In 2018, the recycling rate of municipal solid waste (including recyclable waste, bulk waste, and food waste) has reached about $60 \%$ [17], 
which will be in line with the trend of a "zero waste" policy launched by the EPA. The information about the status of food waste management and its regulatory promotion will be addressed in the following sections.

\subsection{Current Status of Food Waste Management in Taiwan}

\subsubsection{Food Waste Collection System in Taiwan}

According to the definition by the Waste Management Act (WMA) in Taiwan, the waste can be divided into two categories: general waste and industrial waste. The former is very close to the commonly used term "municipal solid waste" (MSW), which can be further grouped into bulk waste (e.g., discarded furniture), recyclable waste (e.g., waste paper), food waste (kitchen waste), hazardous waste (e.g., mercury-containing thermometer), and garbage (i.e., general waste, exclusive from bulk waste, recyclable waste, food waste, and hazardous waste). Herein, food waste can be considered as a special recyclable waste due to its biological constituents for valorization or recycling. On the other hand, industrial waste refers to waste that is generated from industrial activities (but excluding waste generated by the employees themselves). In this regard, the food waste may be generated from non-industrial/residential (i.e., households, institutions, and dwellings) and industrial/commercial (e.g., restaurants, hotels, fast-food chains, and so on) sources. According to the authorization of the WMA, the EPA decided to blanket food waste from the non-industrial sources into the list of "general waste items that should be collected by municipal collection teams" (i.e., one of "mandatory" recyclables). The local governments established the public cleaning teams (or municipal collection teams) to collect the non-recyclable waste and the mandatory recyclables separately. The local enforcement authorities must report the collection amounts of mandatory recyclables (including food waste) monthly to the EPA by the on-line declaration system. Subsequently, the collected mandatory recyclables (including food waste) were sold to private recyclers for the valorization (i.e., organic fertilizer, animal feeds, and so on). Income from sales of recyclable materials from those collected from the public cleaning teams shall be fed back at a specified ratio to the people (or community) and workers who participated. The food waste generated from the industrial sources also can be collected by municipal collection teams, or be commissioned to the legal waste clearance (collection) facilities. These collection teams or facilities must declare the collected amount monthly to the EPA by the on-line reporting system. Figure 2 shows the current flows of the food waste collection systems and valorization options in Taiwan.

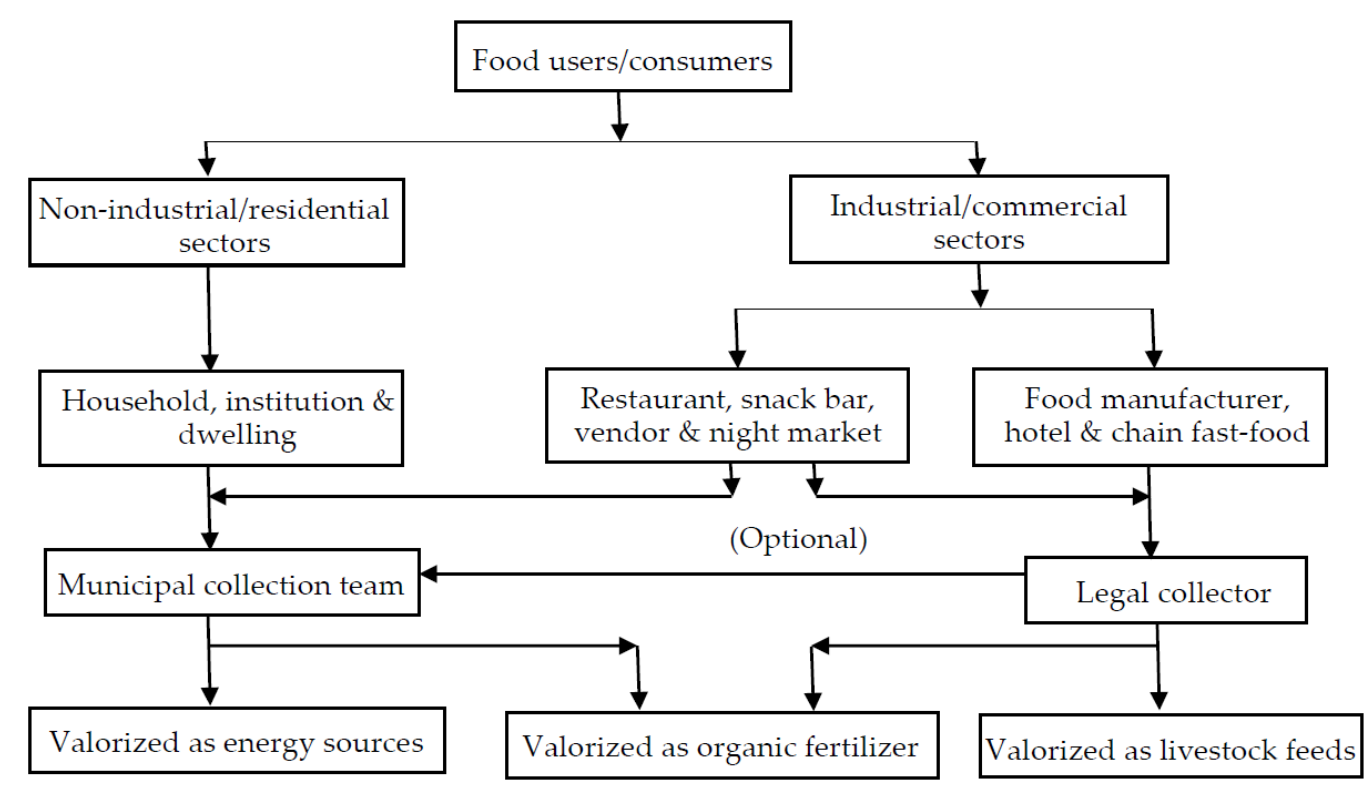

Figure 2. Flows of the food waste collection systems and valorization options in Taiwan. 


\subsubsection{Food Waste Collection and Valorization in Taiwan}

According to the on-line declared data from the municipal collection teams [20], Figure 3 showed the collected amounts of food waste since 2003. Significantly, it increased from about 168,600 metric tons in 2003 to the maximal amount (i.e., 834,500 metric tons) in 2012. Meanwhile, the regulatory promotion of recycling as feedstuff for organic fertilizer, cultivation soil, soil conditioner, or feed for livestock animals (especially for swine) was also promulgated during this period (subsequently described in the Section 3.2.). Thereafter, the collected amounts of food waste indicated a decreasing trend from about 795,000 metric tons in 2013 to 595,000 metric tons in 2018 due to the reduction policy in food loss and waste promoted by the EPA and businesses (or retailers). This trend was similar to that in South Korea because the government implemented the strict recycling and waste reduction policy since 2005 [13]. On the other hand, the decreasing trend in pig feed valorization may be attributed to a decline in the swine-raising industry [23], and the "food safety scandal" that happened in Taiwan in September 2014 [16]. In this regard, the government promulgated the strict regulation that the pig farms must meet certain requirements to reduce the risk of spreading unwanted diseases. It should be noted that the actual amounts of food waste generation in Taiwan could exceed the reported amount because of the following reasons:

- $\quad$ Partial food waste from private collectors was directly utilized as feed for livestock animals without reporting to the local governments.

- $\quad$ Food waste may be mixed together with garbage and then sent to the MSW incineration plants. However, this approach would not have environmental nor energy sustainability due to additional energy consumption and air pollution.

- In recent years, the local and central governments in Taiwan promoted the reduction in food loss and waste (FLW) throughout the entire food supply chain [24].

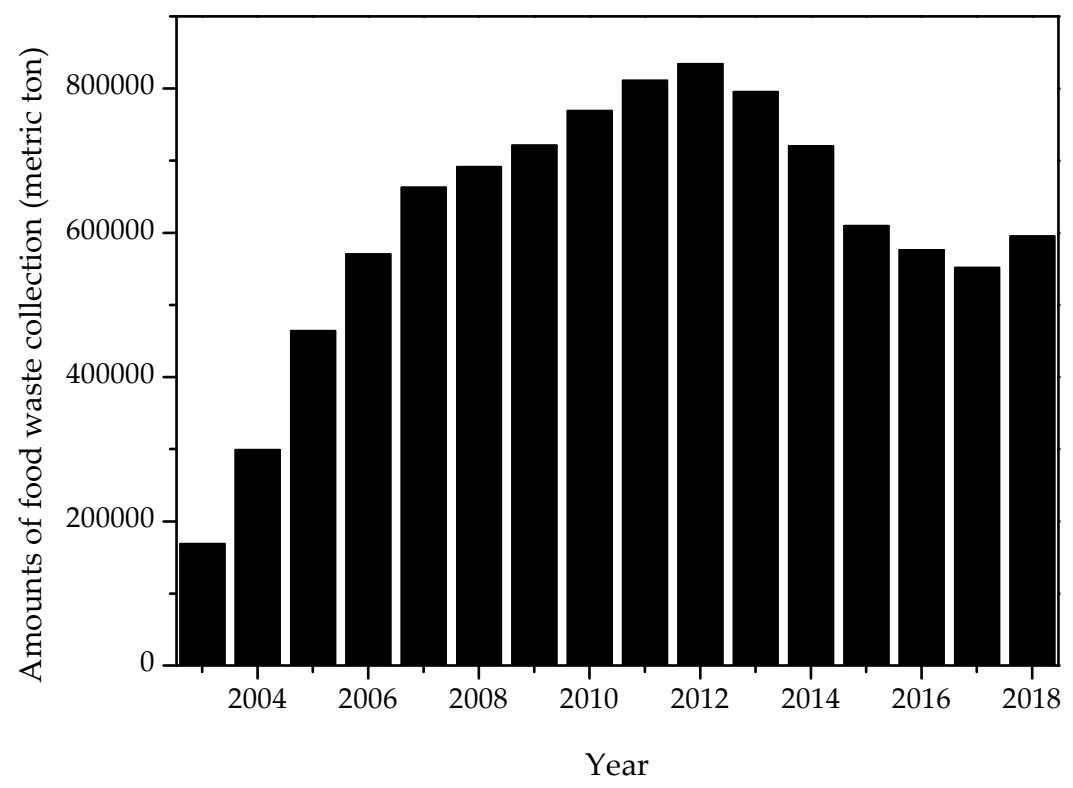

Figure 3. Amounts of food waste collection in Taiwan [17].

Regarding the current valorization methods of the collected food waste, Table 1 summarized their corresponding amounts based on the official statistics [17]. These valorization methods were further described as follows: 
Table 1. Valorization methods of the collected food waste in Taiwan since $2003^{a}$.

\begin{tabular}{ccccc}
\hline Year & Composting & Pig Feed & Other Methods & Sum \\
\hline 2003 & 23,092 & 140,090 & 5419 & 168,601 \\
\hline 2004 & 66,839 & 223,765 & 8661 & 299,265 \\
\hline 2005 & 97,535 & 359,821 & 6844 & 464,200 \\
\hline 2006 & 112,666 & 452,550 & 4961 & 570,177 \\
\hline 2007 & 144,626 & 514,230 & 3934 & 662,790 \\
\hline 2008 & 164,586 & 522,854 & 3754 & 691,194 \\
\hline 2009 & 179,306 & 537,881 & 4284 & 721,471 \\
\hline 2010 & 208,881 & 554,245 & 6038 & 769,164 \\
\hline 2011 & 261,532 & 545,610 & 4076 & 811,198 \\
\hline 2012 & 243,840 & 588,808 & 1893 & 834,541 \\
\hline 2013 & 226,074 & 567,621 & 1519 & 795,214 \\
\hline 2014 & 204,472 & 514,770 & 1132 & 720,374 \\
\hline 2015 & 197,097 & 408,533 & 4076 & 609,706 \\
\hline 2016 & 197,308 & 372,280 & 6345 & 575,933 \\
\hline 2017 & 204,596 & 343,905 & 2828 & 551,329 \\
\hline & & a Source $[17] ;$ unit: metric ton. & &
\end{tabular}

\section{Composting}

The main purposes of this valorization method were to produce organic fertilizer, cultivation soil, or soil conditioner [25,26]. During the composting process, some probiotic microbes were often added to promote the biological decomposition of food waste. In Taiwan, the organic fertilizer produced from the composting plants was mostly applied in the cultivation of vegetables (e.g., cabbage), fruits (e.g., pineapple), and special crops (e.g., tea). For example, an official food-waste-composting plant, located in Tainan city, produced about 1000 metric tons of compost products, which were distributed by the farmer associations at a price of about NT\$5/kg (US\$0.17/kg). It should be noted that the valorization for producing organic fertilizer must be in accordance with the Fertilizer Management Act and the Waste Management Act, which will be described in the Section 3.2.

Pig Feed

Traditionally, farmers have fed food waste to livestock because this approach reduced the amount of biological waste that was carried into sanitary landfills or incineration plants, while helping farmers lower their operation costs [27]. In this regard, over two thirds of food waste collected in Taiwan was thermally processed and then utilized as pig feed, as listed in Table 1 . However, this valorization option must be also compliance with the Animal Industry Act and the Waste Management Act, which will be addressed in the Section 3.2. Listed in Table 1 also are the amounts of the food waste valorization for pig feed, indicating a decreasing trend in recent years because of the tighter legal restrictions as mentioned above.

\section{Other Valorization Methods}

The food waste was also utilized as feedstock for producing animal feed and energy (i.e., biogas-to-power and waste-to-power generated by an MSW incinerator). The biogas-to-power was derived from anaerobic digestion and power generation system in the livestock farms $[18,19,28]$. By contrast, the waste-to-power means that fresh or dewatered food waste was burned in the municipal solid waste incinerators [29]. The utilization as feedstock for producing animal feed should be handled 
in accordance with the Feed Management Act. However, the energy use must comply with the Renewable Energy Development Act. These regulations will be briefly summarized in the Section 3.2.

\subsection{Regulatory Promotions for Valorizing Food Waste in Taiwan}

Due to the biological characteristics of food waste and its valorization for the production of chemicals, materials, and biofuels, the central governing authorities (i.e., EPA, COA, and MOEA) jointly promulgated the regulatory promotions for turning it into value-added resources, which will be described below.

\subsubsection{Waste Management Act}

This Act is sometimes called as the Waste Disposal Act, which was recently revised on June 14, 2017. Basically, it was formulated for the effective clearance and disposal of waste, improvement of environmental sanitation and maintenance of public health. In order to promote the utilization of food waste as available resources, the central governing agency (i.e., the EPA) promulgated some regulations under the authorization of this Act, which were further described below:

Being Listed as One of the Regulated Recyclable Wastes

Due to the availability of organic constituents, the EPA has announced that food waste was listed as one of the recyclable wastes generated from residential, commercial, and industrial sectors. In this regard, the food waste valorization system can be integrated into the 4-in-1 Recycling Program [15,16]. Subsequently, residents in Taiwan are voluntarily required to separate general waste from food waste, which will be sent it to municipal collection teams (organized by local governments). These official collection organizations must report the collected amounts of mandatory recyclable wastes (including food waste) monthly to the central governing agency (i.e., the EPA) by the on-line declaration system.

Specifying Its Reuse Management Methods

The EPA has announced that the valorization methods of food waste only included the organic fertilizers, cultivation (potting) soil, materials for soil improvement, animal feeds, and fuels or fuels for renewable bioenergy. These management methods also should be handled in accordance with the Act and other relevant laws, which include the Fertilizer Management Act, the Feed Management Act, and the Renewable Energy Development Act. In a previous paper [18], it was reported that the first food waste-to-bioenergy plant in Taiwan will be commercially operated in 2019. The plant co-anaerobically utilized food waste and crop residues (e.g., rice straw) to generate biogas and solid digestate. The former was further used to generate electricity, but the latter was utilized as an organic fertilizer. On the other hand, the products derived from the specified valorization method should be in compliance with the national/international standards, or related regulations.

Requiring the Processing Conditions When Utilizing It as an Animal Feed Directly

In order to prevent the microbiological contamination and reduce the odor problem, food waste should be continuously stirred while cooking at a high core temperature $\left(>90^{\circ} \mathrm{C}\right)$ for over $1 \mathrm{~h}$ before valorization for the feeds of even-toed ungulates.

Limiting Its Inflow into Food Production and the Sales Chain

In order to assure food safety and prevent the "waste cooking oil incident" from happening again [16], the valorization products derived from food waste were limited to inflow into food production and the sales chain for utilization as food feedstocks. 


\subsubsection{Fertilizer Management Act}

The Fertilizer Management Act, revised on 2002 June 19, was enacted to ensure wholesome regulation of fertilizers and to maintain the quality of the fertilizers in order to sustain soil fertility, enhance agricultural productivity, and protect the environment. The term fertilizer was defined as a material that provides plants with nutrients or promotes nutrients utilization by plants. Furthermore, compost refers to a fertilizer derived from the fermentation of organic materials. According to the authorization of the Act, the central governing agency (i.e., the COA) shall determine and promulgate the categories, types, and specifications of fertilizers. Table 2 listed the composition specifications/limits of organic fertilizer (miscellaneous compost items 5-11) derived from food waste in Taiwan [22], including the requirement specifications for the main constituents and the content limits of hazardous constituents.

Table 2. Composition specifications for organic fertilizers derived from food waste in Taiwan [22].

\begin{tabular}{cc}
\hline Constituent & Specification (Maximum/Minimum Limit) \\
\hline Main constituents & $\geqq 50 \%$ \\
Organic matter & $\geqq 0.6 \%, \leq 5.0 \%$ \\
Total nitrogen & $\geqq 0.3 \%, \leq 6.0 \%$ \\
Total phosphoric anhydride & $\geqq 0.3 \%, \leq 4.0 \%$ \\
Total potassium oxide & $\leq 25.0 \mathrm{mg}$ \\
Hazardous constituents & $\leq 2.0 \mathrm{mg}$ \\
Arsenic $(\mathrm{As})$ & $\leq 50 \mathrm{mg}$ \\
Cadmium $(\mathrm{Cd})$ & $\leq 100 \mathrm{mg}$ \\
Chromium $(\mathrm{Cr})$ & $\leq 1.0 \mathrm{mg}$ \\
Copper $(\mathrm{Cu})$ & $\leq 25.0 \mathrm{mg}$ \\
Mercury $(\mathrm{Hg})$ & $\leq 150 \mathrm{mg}$ \\
Nickel $(\mathrm{Ni})$ & $\leq 500 \mathrm{mg}$ \\
Lead $(\mathrm{Pb})$ & \\
Zinc $(\mathrm{Zn})$ &
\end{tabular}

In addition, the miscellaneous compost items 5-11 must also meet the following limitation requirements:

- The resulting fertilizer must not be mixed in chemical fertilizers or minerals.

- The moisture should be below $4.0 \%$.

- The pH value should range from 5.0 to 9.0, and it should be labeled as such.

- $\quad$ The ratio of carbon-to-nitrogen should range from 10.0 to 20.0.

- The sodium and chlorine contents must not exceed $4.0 \%$ and $6.0 \%$, respectively.

\subsubsection{Feed Management Act}

The Feed Management Act was established to maintain the quality of feeds and promote the development of the animal husbandry and the aquaculture industry so as to maintain the public health. This Act was recently revised on February 4, 2015. Regarding the term "feed" in this Act, it refers to foodstuffs that provide nutrition to, or promote healthy growth of, livestock, poultry, and aquatic animals In this regard, the feed includes plant-based feed, animal-based feed, feed supplement (i.e., minerals, vitamins, amino acids), and formulated feed (i.e., formulated mixture or compound of two or more of the abovementioned feeds). Based on the Act, food waste can be legally processed to produce the formulated feed for the livestock (especially for swine) due to the cost reduction in the feed expenditure and effective reduction in the biological waste. It means that the feed derived from food waste must be processed by the legal waste recycling factories according to the WMA. 


\subsubsection{Animal Industry Act}

This Act, recently revised on 24 November 2010, was drawn up for the purposes of regulating and providing guidance to the livestock/poultry farming business, preventing environmental pollution, and facilitating the development of the animal industry. Regarding the environmental pollution prevention/control as a result of livestock excrement and manure, the farm owners must submit a plan that is reviewed and approved by the environmental protection authority, and also meet the environmental standards during the business period. In addition, the livestock/poultry sectors contributed a significant share to anthropogenic emissions of greenhouse gases [30], especially in methane (the most important component in the biogas). In this regard, the central governing authorities (i.e., the EPA and the COA) promoted the installation of the anaerobic digestion (AD) system in the large-scale swine farms based on the dual benefits of environmental control and biogas-to-power.

\subsubsection{Renewable Energy Development Act}

In Taiwan, the central legislation for promoting renewable energy and establishing green energy industry was built on the Renewable Energy Development Act (REDA), which was first passed on 8 July 2009 and recently revised on 1 May 2019. Based on the definition by the REDA, biomass energy refers to energy generated from direct use or treatment of agriculture and forestry vegetation, marsh gas (biogas), and domestic organic waste. In order to achieve the promotion goal (i.e., $27 \mathrm{GW}$ ) of renewable energy installation in 2025, the central governing agency (i.e., the MOEA) promulgated some regulations for the installation of renewable energy system under the authorization of this Act, especially for wind power, photovoltaic power, and biogas-to-power. Among these promotion measures, the feed-in-tariff (FIT) mechanism, financial supports, and funding subsidies may play a vital role in the installation of the renewable electricity system. In brief, the FIT scheme provided a long-term financial stability (usually fixed at 20 years) for compensating the renewable electricity investors at a guaranteed (fixed) rate [31-33]. Regarding the FIT rates of biogas-to-power in Taiwan during the period of 2010-2020, it showed an upward trend, increasing from $2.0615 \mathrm{NT} \$ / \mathrm{kW}-\mathrm{h}$ in 2010 to $5.1176 \mathrm{NT} \$ / \mathrm{kW}-\mathrm{h}$ in 2020 ( 1 US\$ $\approx 30$ NT\$).

\section{Conclusions and Prospects}

Under the authorization of the Waste Management Act, food waste was considered as one of "mandatory" recyclables by the Taiwan EPA for the production of organic fertilizer, animal feed, and bioenergy because these valorization options are aimed at increasing the resource-use efficiency and reducing the depletion of natural resources from the viewpoint of a circular bioeconomy. With the implementation of food waste valorization program since 2003, its collected amounts from residential and commercial sectors in Taiwan indicated a significant increase from about 470 metric tons per day collected in 2003 to about 1700 metric tons in 2018. Of the methods used to valorize food waste, about $60-75 \%$ undergoes steam treatment to make pig feed, while $25-40 \%$ enters composting systems. In addition, under the frameworks of the Fertilizer Management, the Feed Management Act, and the Renewable Energy Development Act triggered by other central governing authorities (i.e., COA and MOEA), current regulatory and technological measures for turning food waste into valuable by-products, including organic fertilizers, natural products, animal feed, biofuels, and bioelectricity, have caused significant benefits in the resource recovery and MSW management. However, it should be pointed out that environmental and energy sustainability for these food waste valorization options must be properly evaluated through an overall lifecycle assessment. To manage the treatment and disposal of food waste by more environmentally friendly and healthy ways, the Taiwan government currently provides financial support to establish anaerobic digestion and aerobic composting plants for turning food waste into organic fertilizers and biogas-to-electricity. On the other hand, reducing food loss and waste (FLW) throughout the entire food supply chain (FSC) has been widely recognized in 
recent years. The influence of FLW regulations on food waste collection, generation, valorization, and consumer behavior towards the food supply chain will be more significant in the near future.

Funding: This research received no external funding.

Acknowledgments: The author expressed sincere appreciation to Yu-Quan Lin for the assistance in drawing the figure.

Conflicts of Interest: The authors declare no conflict of interest.

\section{References}

1. Tchobanoglous, G.; Theisen, H.; Vigil, S.A. Integrated Solid Waste Management: Engineering Principles and Management Issues; McGraw-Hill: New York, NY, USA, 1993; pp. 39-68.

2. Khoo, H.H.; Lim, T.Z.; Tan, R.B.H. Food waste conversion options in Singapore: Environmental impacts based on an LCA perspective. Sci. Total Environ. 2010, 408, 1367-1373. [CrossRef] [PubMed]

3. Thi, N.B.D.; Kumar, G.; Lin, C.Y. An overview of food waste management in developing countries: Current status and future perspective. J. Environ. Manag. 2015, 157, 220-229. [CrossRef] [PubMed]

4. Maina, S.; Kachrimanidou, V.; Koutinas, A. A roadmap towards a circular and sustainable bioeconomy through waste valorization. Curr. Opin. Green Sustain. Chem. 2017, 8, 18-23. [CrossRef]

5. Dahiya, S.; Kumar, A.N.; Sravan, J.S.; Chatterjee, S.; Sarkar, O.; Mohan, S.V. Food waste biorefinery: Sustainable strategy for circular bioeconomy. Bioresour. Technol. 2018, 248, 2-12. [CrossRef] [PubMed]

6. Lin, C.S.K.; Pfaltzgraff, L.A.; Herrero-Davila, L.; Mubofu, E.B.; Abderrahim, S.; Clark, J.H.; Koutinas, A.A.; Kopsahelis, N.; Stamatelatou, K.; Dickson, F.; et al. Food waste as a valuable resource for the production chemicals, materials and fuels. Current situation and global perspective. Energy Environ. Sci. 2013, 6, 426-464. [CrossRef]

7. Baiano, A. Recovery of biomolecules from food waste-A review. Molecules 2014, 19, 14821-14842. [CrossRef]

8. Lin, C.S.K.; Koutinas, A.A.; Stamatelatou, K.; Mubofu, E.B.; Matharu, A.S.; Kopsahelis, N.; Pfaltzgraff, L.A.; Clark, J.H.; Papanikolaou, S.; Kwan, T.H.; et al. Current status and future trends in food waste valorization for the production chemicals, materials and fuels: A global perspective. BiofuelsBioprod. Biorefining 2014, 8, 686-715. [CrossRef]

9. Vandermeersch, T.; Alvarenga, R.A.F.; Ragaert, P.; Dewulf, J. Environmental sustainability assessment of food waste valorization options. Resour. Conserv. Recycl. 2014, 87, 57-64. [CrossRef]

10. Imbert, E. Food waste valorization options: Opportunities from the bioeconomy. Open Agric. 2017, 2, 195-204. [CrossRef]

11. Ong, K.L.; Kaur, G.; Pensupa, N.; Uisan, K.; Lin, C.S.K. Trends in food waste valorization for the production of chemicals, materials and fuels: Case study South and Southeast Asia. Bioresour. Technol. 2018, 248, 100-112. [CrossRef]

12. Cecchi, F.; Cavinato, C. Smart approaches to food waste final disposal. Int. J. Environ. Res. Public Health 2019, 16, 2860. [CrossRef]

13. Ministry of Environment (MOE, Korea). Ministry of Environment; MOE: Soul, Korea, 2015. Available online: http://eng.me.go.kr/eng/file/readDownloadFile.do?fileId=115224\&fileSeq=1\&openYn=Y (accessed on 20 April 2020).

14. Lim, W.J; Chin, N.L.; Yusof, A.Y.; Yahya, A.; Tee, T.P. Food waste handling in Malaysia and comparison with other Asian countries. Int. Food Res. J. 2016, 23, S1-S6.

15. Chang, Y.M.; Liu, C.C.; Hung, C.Y.; Hu, A.; Chen, S.S. Change in MSW characteristics under recent strategies in Taiwan. Waste Manag. 2008, 28, 2443-2455. [CrossRef]

16. Tsai, W.T. Mandatory recycling of waste cooking oil from residential and commercial sectors in Taiwan. Resources 2019, 8, 38. [CrossRef]

17. Environmental Protection Administration (EPA, Taiwan). Yearbook of Environmental Protection Statistics 2018; EPA: Taipei, Taiwan, 2019.

18. Tsai, W.T. Regulatory promotion and benefit analysis of biogas-power and biogas-digestate from anaerobic digestion in Taiwan's livestock industry. Fermentation 2018, 4, 57. [CrossRef]

19. Lai, C.M.; Ke, G.R.; Chung, M.Y. Potentials of food wastes for power generation and energy conservation in Taiwan. Renew. Energy 2009, 34, 1913-1915. [CrossRef] 
20. Tsai, W.T. Promoting the circular economy via waste-to-power (WTP) in Taiwan. Resources 2019, 8, 95. [CrossRef]

21. Wang, W.H.; Lin, C.Y.; Ishcol, M.R.C.; Urbina, A.N.; Assavalapsakul, W.; Thitithanyanont, A.; Lu, P.L.; Chen, Y.H.; Wang, S.F. Detection of African swine fever virus in pork products brought to Taiwan by travelers. Emerg. Microbes Infect. 2019, 8, 100-102. [CrossRef]

22. Laws and Regulation Retrieving System. Available online: https://law.moj.gov.tw/Eng/index.aspx (accessed on 10 February 2020).

23. Council of Agriculture (COA). Agriculture Statistics Yearbook 2018; COA: Taipei, Taiwan, 2019.

24. Ishangulyyev, R.; Kim, S.; Lee, S.H. Understanding food loss and waste-Why are we losing and wasting food? Foods 2019, 8, 297. [CrossRef]

25. Tsai, W.T. Management considerations and environmental benefit analysis for turning food garbage into agricultural resources. Bioresour. Technol. 2008, 99, 5309-5316. [CrossRef]

26. Chen, Y.T. A cost analysis of food waste composting in Taiwan. Sustainability 2016, 8, 1210. [CrossRef]

27. Chen, K.L.; Chang, H.J.; Yang, C.K.; You, S.H.; Jenq, H.D.; Yu, B. Effect of dietary inclusion of dehydrated food waste products on Taiwan native chicken (Taishi No. 13). Asian-Australas. J. Anim. Sci. 2007, 20, 754-760. [CrossRef]

28. Dung, T.N.B.; Sen, B.; Chen, C.C.; Kumar, G.; Lin, C.Y. Food waste to bioenergy via anaerobic processes. Energy Procedia 2014, 61, 307-312. [CrossRef]

29. Tsai, W.T. Analysis of municipal solid waste incineration plants for promoting power generation efficiency in Taiwan. J. Mater. Cycles Waste Manag. 2016, 18, 393-398. [CrossRef]

30. Food and Agriculture Organization of United States (FAO). Tackling Climate Change through Livestock; FAO: Rome, Italy, 2013.

31. Lesser, J.A.; Su, X. Design of an economically efficient feed-in tariff structure for renewable energy development. Energy Policy 2008, 36, 981-990. [CrossRef]

32. Wang, K.M.; Cheng, Y.J. The evolution of feed-in tariff policy in Taiwan. Energy Strategy Rev. 2012, 1, $130-133$. [CrossRef]

33. Tsai, W.T. Feed-in tariff promotion and innovative measures for renewable electricity: Taiwan case analysis. Renew. Sustain. Energy Rev. 2014, 40, 1126-1132. [CrossRef]

(C) 2020 by the author. Licensee MDPI, Basel, Switzerland. This article is an open access article distributed under the terms and conditions of the Creative Commons Attribution (CC BY) license (http://creativecommons.org/licenses/by/4.0/). 